\title{
Effects of Fine-Grained Particles' Migration and Clogging in Porous Media on Gas Production from Hydrate-Bearing Sediments
}

\author{
Jongwon Jung $\mathbb{D},{ }^{1}$ Hongsig Kang $\mathbb{D}^{1},{ }^{1}$ Shuang Cindy Cao, ${ }^{2}$ Riyadh I. Al-Raoush $\left(\mathbb{D},{ }^{3}\right.$ \\ Khalid Alshibli, ${ }^{4}$ and Joo Yong Lee $\mathbb{B}^{5}$ \\ ${ }^{1}$ School of Civil Engineering, Chungbuk National University, Cheongju-si, Chungbuk 28644, Republic of Korea \\ ${ }^{2}$ Department of Civil and Environmental Engineering, Louisiana State University, Baton Rouge, LA 70803, USA \\ ${ }^{3}$ Department of Civil \& Architectural Engineering, Qatar University, P.O. Box 2713, Doha, Qatar \\ ${ }^{4}$ Department of Civil and Environmental Engineering, The University of Tennessee, Knoxville, TN 37996, USA \\ ${ }^{5}$ Petroleum and Marine Research Division, Korea Institute of Geoscience and Mineral Resources, Daejeon, Republic of Korea
}

Correspondence should be addressed to Joo Yong Lee; jyl@kigam.re.kr

Received 7 January 2019; Accepted 16 April 2019; Published 23 May 2019

Guest Editor: Andrew Bunger

Copyright (C) 2019 Jongwon Jung et al. This is an open access article distributed under the Creative Commons Attribution License, which permits unrestricted use, distribution, and reproduction in any medium, provided the original work is properly cited. The publication of this article was funded by Qatar National Library.

\begin{abstract}
The migration of fine particles in porous media has been studied for different applications, including gas production from hydratebearing sediments. The clogging behavior of fine particles is affected by fine particle-pore throat size ratio, fine particle concentration, ionic concentration of fluids, and single/multiphase fluid flow. While previous studies presented valuable results, the data are not enough to cover a broad range of particle types and sizes and pore throat size in natural hydrate-bearing sediments. This paper presents a novel micromodel to investigate the effects of fine particle-pore throat size ratio, fine concentration, ionic concentration of fluid, and single/multiphase fluid flow on clogging or bridging in porous media. The results show that (1) the concentration of fine particles required to form clogging and/or bridging in pores decreased with the decrease in fine particle-pore throat size ratio, (2) the effects of ionic concentration of fluid on clogging behaviors depend on the types of fine particles, and (3) fine particles prefer to accumulate along the deionized water- (DW-) $\mathrm{CO}_{2}$ interface and migrate together, which in turn easily causes clogging in pores. As a result, multiphase fluid flow during gas production from hydratebearing sediments could easily develop clogging in pore throats, where the relative permeability of $\mathrm{DW}-\mathrm{CO}_{2}$ in porous media decreases. Accordingly, the relatively permeability of porous media should be evaluated by considering the clogging behavior of fines.
\end{abstract}

\section{Introduction}

The migration of fine particles in porous media has been studied for different applications such as oil extraction [1, $2]$, pore clogging by fines [3-5], sand production in oil reservoirs [6], fracturing in sediments during production of shale oil and gas [7], and gas production from hydratebearing sediments $[8,9]$. The migration of fine particles has been studied in laboratory experiments using twodimensional (2D) microfluidic pore models at the microscale $[10,11]$ and three-dimensional (3D) porous sediment models at the macroscale [12-16] to better understand the migration behavior of fine particles and its impacts on bridging and/or clogging in porous media [8-11, 17-23]. Previous studies have identified four distinct mechanisms that are influenced by two critical size ratios: the ratio of fine particle diameter to pore throat width $(\mathrm{d} / \mathrm{o})$ and the ratio of fine particle diameter to host particle diameter $(d / D)$ (Figure 1, [14]). They are piping and no interaction $(d / o<0.01$ or $d / D<0.067)$, multiparticle blocking or bridging $(0.01<d / o<0.6$ or $0.067<d / D<0.2)$, and blocking/no invasion $(d / o>0.6$ or $d / D>0.2)$ (Figure 1). Also, previous 


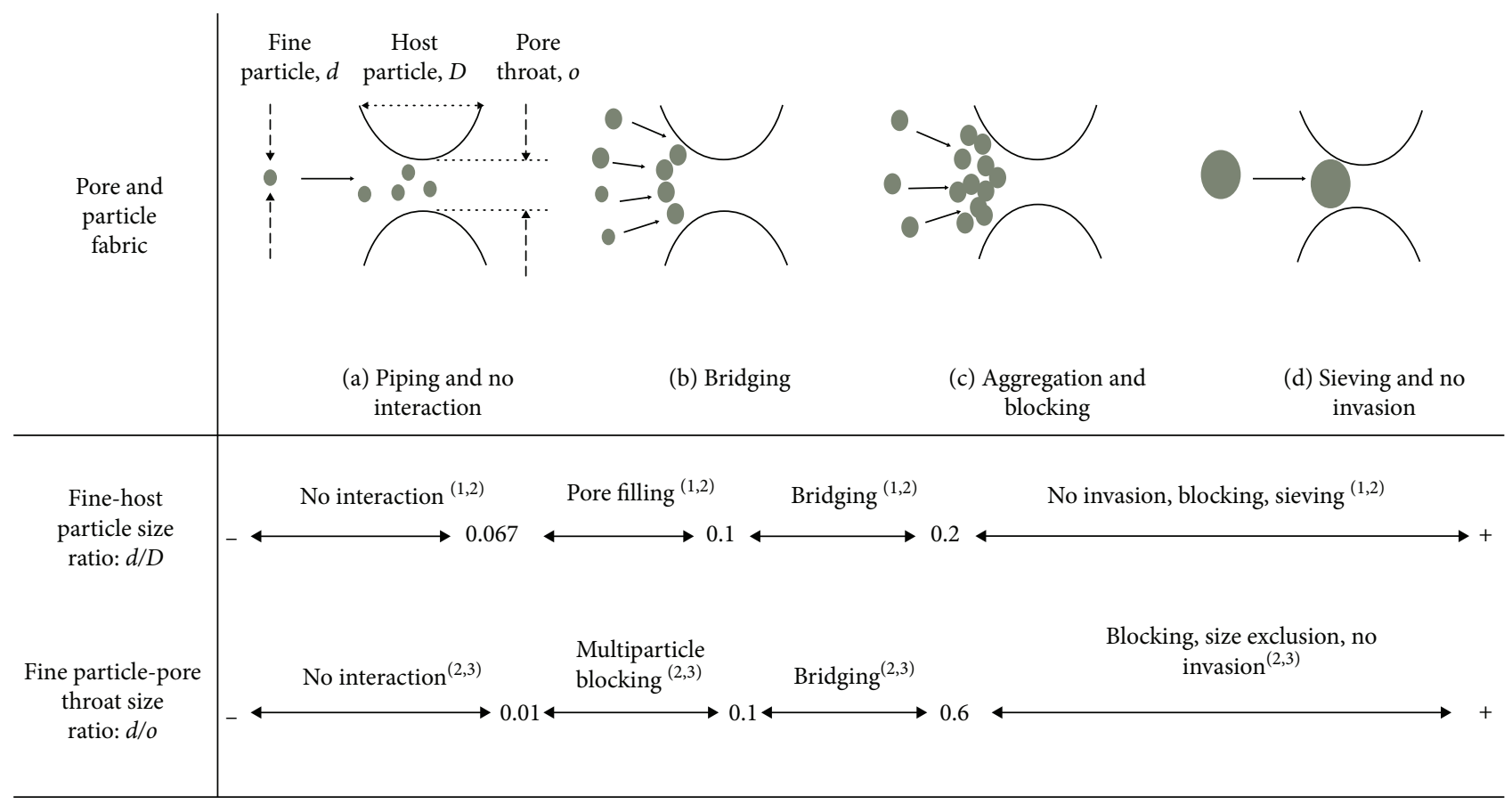

*(1) Bingo et al, 1994; (2) Oyeneyin et al, 1995; (3) Khilar and Fogler, 1998.

Figure 1: Main mechanisms for fines migrating and clogging at pore throats, classified based on critical size ratios $(d / D, d / o)$, where $D$ is the host particle diameter, $d$ is the diameter of fine particle, and $o$ is the pore throat width [8].

studies have reported that clogging occurs more easily at higher concentration of fine particles $[10,24,25]$ and at the lower flow rate because a higher flow rate prevents fine particles to form bridging or/and clogging due to disruptions by pressure distribution or flow reversals $[2,12]$.

In addition to the effect of fine particles size relative to the pore throat size, parameters such as fine concentration, flow rate, pore-fluid chemistry influence, and fine migration/clogging behavior $[8,26]$. Fine particles have unbalanced surface charge densities and specific surface areas. Their electrical surface charge distribution and fine particle shapes result in three electrical interactions such as electrostatic Coulombic forces, the Sogami-Ise model, and Van der Waals attraction and double layer repulsion that is described by the Derjaguin-Landau-Verwey-Overbeek (DLVO) theory, which influence the aggregation of fine particles. Thus, the ionic concentration of the fluid affects particle interactions and causes the aggregation due to the above three electrical interactions, which links to the ratios of fine particle size and the pore throat size [8].

A multiphase fluid flow is defined as a simultaneous flow of two or more fluids with different phases (i.e., gas or liquid). Previous studies have shown that multiphase fluid flow has more impact on fine particle accumulation along the fluidfluid interface resulting in fine clogging/bridging in porous media $[2,8,9,26,27]$. Therefore, for a given ratio of fine particle size to the pore throat size, fine clogging/bridging in porous media during a multiphase fluids flow requires less fine concentration as compared to a single-phase flow $[8,26]$.

In natural conditions, multiphase flow occurs during methane extraction from gas hydrate. Also, porewater freshening occurs during gas hydrate dissociation caused by release of freshwater coming from hydrates. Both a multiphase fluid flow and a porewater freshening influence on fine particle migration and clogging behaviors with the size ratio of fine particles and pore throats. There are limited experimental studies on fine particle migration and clogging during methane extraction from hydrate [8]. [8] experiments were conducted for pore throat sizes between $20 \mu \mathrm{m}$ and $100 \mu \mathrm{m}$.

The objectives of this study are (1) to investigate the impact of fine migration and potential clogging behaviors of fine particles during gas hydrate dissociation in a wide range of pore throat sizes using a $2 \mathrm{D}$ micromodel system and (2) to present a "clogging map" to be used to understand the clogging potential of natural hydrate-bearing sediments during gas production with basic information such as mineralogy and grain size distribution. A wide range of fines sizes between $20 \mu \mathrm{m}$ and $200 \mu \mathrm{m}$ and particle concentrations between $0.1 \%$ and $20 \%$ were used in the study.

\section{Experimental Study}

2.1. Materials. Six fine particles that are widely common in natural gas hydrate-bearing sediments were selected for this study, namely, silica, silt, mica, calcium carbonate (primarily calcite, $\mathrm{CaCO}_{3}$ ), diatom, kaolin (primarily kaolinite), and bentonite (primarily montmorillonite) [28-30]. Table 1 lists the median particle size of each fine particle. In this paper, the concentrations of fine particles are calculated as the weights of fine particles and fluid (in weight/weight percent $(w / w \%))$, which has a wide range between $0.1 \%$ and $20 \%$ (i.e., $0.1 \%, 0.2 \%, 0.5 \%, 1 \%, 2 \%, 5 \%, 10 \%, 13 \%, 15 \%, 17 \%$, 
TABLE 1: Median particle sizes of the fines used in this study.

\begin{tabular}{lc}
\hline Fine-grained particles & Median particle size $\left(d_{50}\right)(\mu \mathrm{m})$ \\
\hline Silica silt & $10.5^{\mathrm{a}}$ \\
Mica & $17^{\mathrm{a}}$ \\
$\mathrm{CaCO}_{3}$ & $8^{\mathrm{a}}$ \\
Diatoms & $10^{\mathrm{a}}$ \\
Kaolinite & 4 \\
Bentonite & $<2^{\mathrm{b}}$ \\
\hline
\end{tabular}

${ }^{\mathrm{a}}$ Data from manufacturer. ${ }^{\mathrm{b}}$ Approximated value from literature (Arnott, 1965).

and $20 \%$ ). Deionized water (DW) and $2 \mathrm{M}$ sodium chloride $(\mathrm{NaCl})$ solution were used as pore fluid to study the effects of ionic concentration on fine migration and clogging.

2.2. Micromodels. The micromodels used in this study were fabricated using polymeric materials known as polydimethylsiloxane (PDMS, [4]). The micromodels were made of a homogeneous $2 \mathrm{D}$ pore network pattern as depicted in Figure 2 and were bonded to a PDMS-coated glass slide. The micromodel measures $20 \mathrm{~mm} \times 10 \mathrm{~mm}$. The circular solid diameter $(D)$ represents the host particle size in sediments. Pore throat widths, $o$, have a wide range of 20,40, $60,100,150,180$, and $200 \mu \mathrm{m}$, which were determined by pore throat sizes in natural sediments. The pore height is $100 \mu \mathrm{m}$, which does not influence the fluid flow and particle migration.

2.3. Experimental Setup. Figure 2 shows a schematic of the experimental setup. The micromodel is placed horizontally on an Olympus IX51-LWD 4X/0.1 microscope. Inlet and outlet ports of the micromodel are connected to a Teledyne ISCO pump and to a syringe pump (NE-1010; Kats Scientific), respectively. The syringe pump (NE-1010; Kats Scientific) injects DW mixed with fines into the micromodel. And then, while the syringe pump (NE-1010; Kats Scientific) controls the imbibition of DW from the micromodel, the Teledyne ISCO pump injects $\mathrm{CO}_{2}$ gas (99.99\%, Airgas) into the micromodel. The system was maintained at $10 \pm 1 \mathrm{kPa}$ by a pressure regulator and the pressure pump at room temperature $\left(25 \pm 1^{\circ} \mathrm{C}\right)$. A filter was placed between the micromodel and the pressure regulator to prevent fine migration into the pressure regulator. The microscope has monitored the channels of micromodels during tests, and the camera captured both images and video (Figure 2).

2.4. Experimental Procedure. After thorough cleaning of the experimental system including micromodel channels, tubings, and its components using absolute ethanol (ACS reagent grade; Mallinckrodt Baker), DW was injected to rinse the system. Then, an experimental setup was dried at room temperature $\left(25 \pm 1^{\circ} \mathrm{C}\right)$ for $72 \mathrm{hr}$ and was assembled (Figure 2). The micromodel was saturated by DW containing fine particles at different concentrations $(0.1 \%, 0.5 \%, 1 \%, 2 \%$, $5 \%, 10 \%, 13 \%, 15 \%, 18 \%$, and $20 \%$ by weight) using the syringe pump. Then, the pressure was increased up to $10 \pm$ $1 \mathrm{kPa}$ using a pressure regulator and the ISCO pump. Both pressure $(10 \pm 1 \mathrm{kPa})$ and temperature $\left(25 \pm 1^{\circ} \mathrm{C}\right)$ were kept constant during all tests. The syringe pump withdrew DW with fine particles from the micromodel at a constant flow rate of $50 \mu \mathrm{l} / \mathrm{min}$. The microscope and the camera monitor fine migration and DW flow through the micromodel, and images were saved for further analysis.

2.4.1. Single-Phase Flow. The micromodel with a $200 \mu \mathrm{m}$ pore throat width was first used. The fine concentration was gradually increased until clogging was observed in the micromodel. At the state of clogging, the fine concentration was labelled as the critical fine concentration for a given pore throat size. Next, the micromodel with a smaller pore throat size (e.g., $180 \mu \mathrm{m}$ ) was used for a given fine concentration, and another critical fine concentration was identified at a given pore throat size. A series of experiments were conducted to determine the critical fine concentration at a given pore throat size.

2.4.2. Multiphase Fluid Flow. The micromodel was saturated with DW mixed with fine particles. A combination of pore throat size and fine concentration was selected such that the pore throats in the micromodel were not clogged after the injection of 100 pore volume of DW containing fines. $\mathrm{CO}_{2}$ was then injected into the micromodel while DW-fine particles were withdrawn using the syringe pump. Both pressure $(10 \pm 1 \mathrm{kPa})$ and temperature $\left(25 \pm 1^{\circ} \mathrm{C}\right)$ were kept constant during experiments. The experiments were repeated for different combinations of pore throat size and fine concentration where clogging was not induced during a singlephase flow.

\section{Results and Discussion}

\subsection{Effects of Particle Concentration and Particle Pore Throat Size Ratio on Clogging Behavior in a Single-Phase Flow}

3.1.1. Particle Concentration. Figure 3 displays a few snapshots of DW injection with kaolinite into the micromodel at various particle concentrations from $0.1 \%$ to $1 \%$. The flow rate $(50 \mu \mathrm{l} / \mathrm{min})$ and pore throat size $(150 \mu \mathrm{m})$ were kept constant for all experiments. Results show that clogging occurs at $0.5 \%$ and $1 \%$ kaolinite particle concentration at a given experimental condition. It implies that the $0.5 \%$ kaolinite is the minimum concentration that causes clogging at pore throats, which can be called as the critical clogging concentration in this study. Note that the critical clogging concentration is defined as the ratio of fine particle mass to liquid mass that induces clogging. For example, $0.5 \%$ kaolinite is the critical clogging concentration at a given condition (e.g., flow rate is $50 \mu \mathrm{l} / \mathrm{min}$, pore throat size is $150 \mu \mathrm{m}$, and fluid type is DW). In general, the critical clogging concentration decreases as the particle-pore throat size ratio increases (Figure 4), which is consistent with previous studies $[8,10,25,26]$.

3.1.2. Particle Pore Throat Size Ratio. Figure 5 shows three images of DW injections with kaolinite into the micromodels with various pore throat sizes from 40 to $100 \mu \mathrm{m}$. The flow rate $(50 \mu \mathrm{l} / \mathrm{min})$ and kaolinite concentration $(0.5 \%)$ were constant for all experiments. Neither bridging nor clogging 


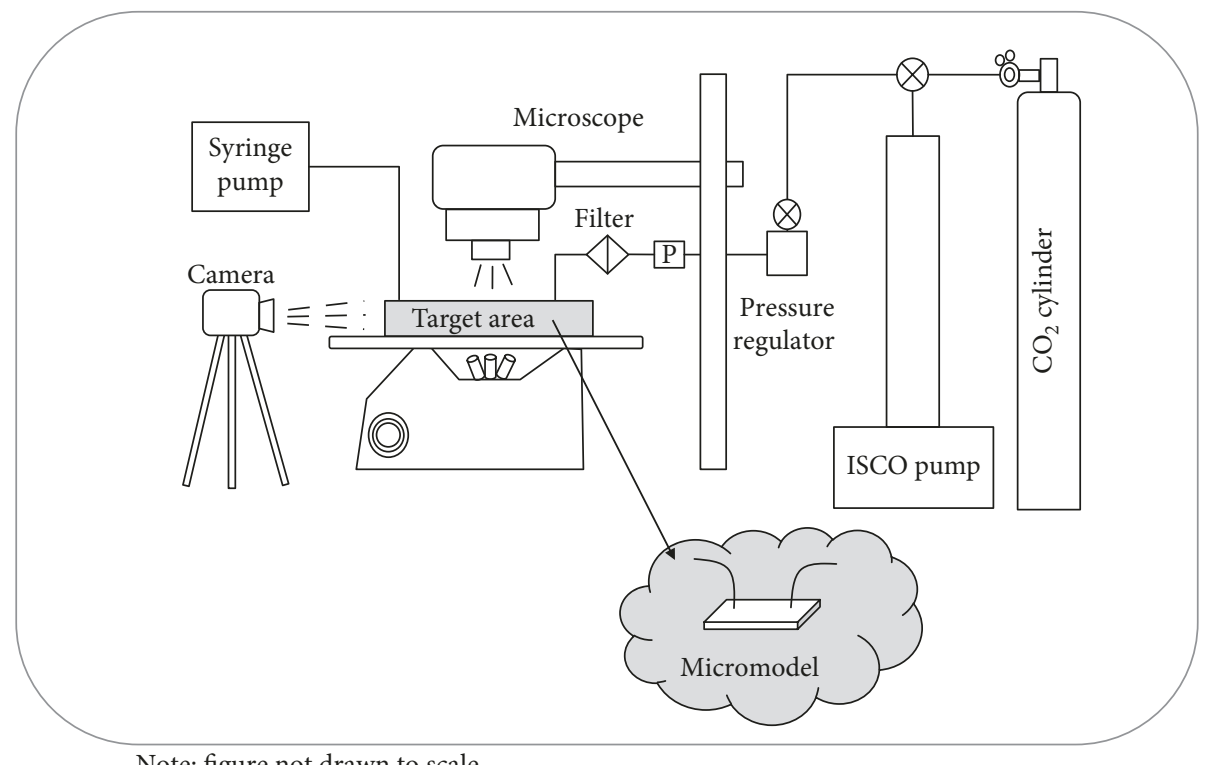

(a)

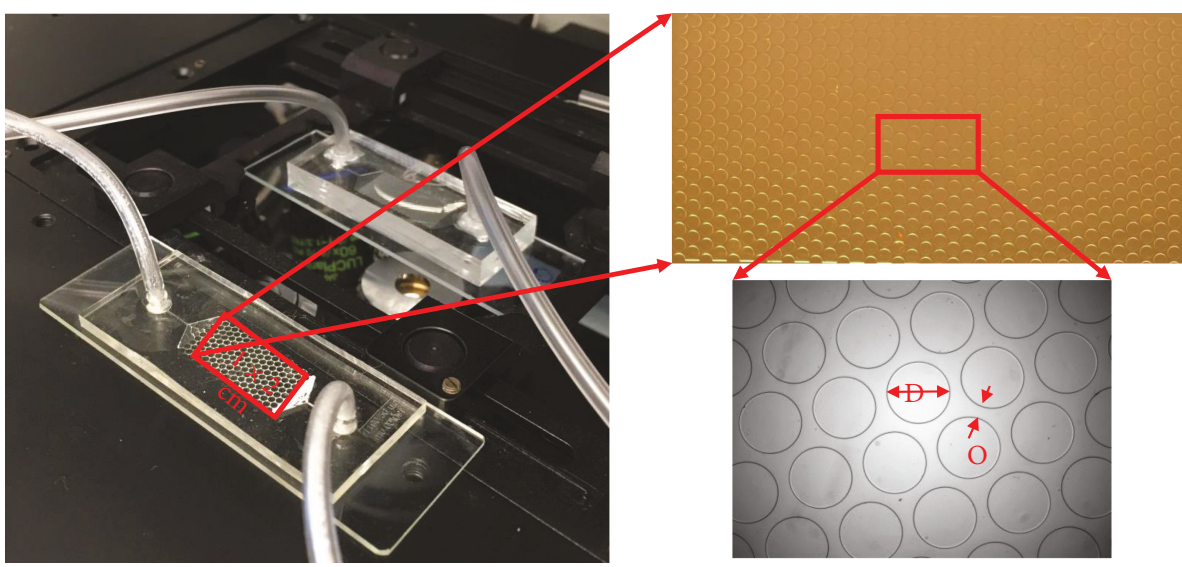

(b)

FIGURE 2: Experimental setup [8, 26].

was observed in the microfluidic pore models at the given pore throat sizes of $60 \mu \mathrm{m}$ and $100 \mu \mathrm{m}$ (flow rate $=50 \mu \mathrm{l}$ / min, kaolinite concentration $=0.5 \%)$. However, clogging occurs at a pore throat size of $40 \mu \mathrm{m}$ at the same flow rate and kaolinite concentration. It implies that clogging easily occurs as pore throat size decreases.

3.2. Effects of Ionic Concentration on Clogging Behavior of Fines in a Single-Phase Flow. Figure 6 shows a few images of pore fluid-specific clogging tendencies and behaviors of diatom, $\mathrm{CaCO}_{3}$, and kaolinite between $\mathrm{DW}$ and 2M-brine. Clogging behavior depends on the type of injected fluid (i.e., DW or 2M-brine) due to the ionic concentration of fluids. For instance, kaolinite particles in $2 \mathrm{M}$-brine $(0.2 \%$ kaolinite concentration) are uniformly dispersed in the $60 \mu \mathrm{m}$ pore throat micromodel, and no clogging is observed in Figure 6(f). In contrast, with the identical geometry and kaolinite concentration, kaolinite particles in DW are locally concentrated at some pore throats that are identified as clogged (red circles in Figure 6(c)). This result provides clear evidence that kaolinite particles clog more easily in DW than in $2 \mathrm{M}$ brine. However, for both diatom and $\mathrm{CaCO}_{3}$ particles, results show the similar clogging tendencies of them in both DW and 2M-brine (Figures 6(a), 6(b), 6(c), and 6(d)). The number of clogging in pores is different between DW and 2M-brine; however, both particles clog in both DW and $2 \mathrm{M}$-brine at the same conditions (i.e., particle size, pore size, and concentration).

Figure 4 shows critical clogging concentrations of all types of fine particles (i.e., silica silt, mica, $\mathrm{CaCO}_{3}$, diatoms, kaolinite, and bentonite) between DW and 2M-brine. A detailed discussion of results follows.

3.2.1. Kaolinite. While fine particle pore throat size ratios were from 0.04 to 0.2 in the previous study [8], a broader range of size ratios is investigated in this study from 0.02 to 0.2 . Thus, new data in the range of size ratio from 0.02 to 0.04 was added onto the "clogging map" including only 


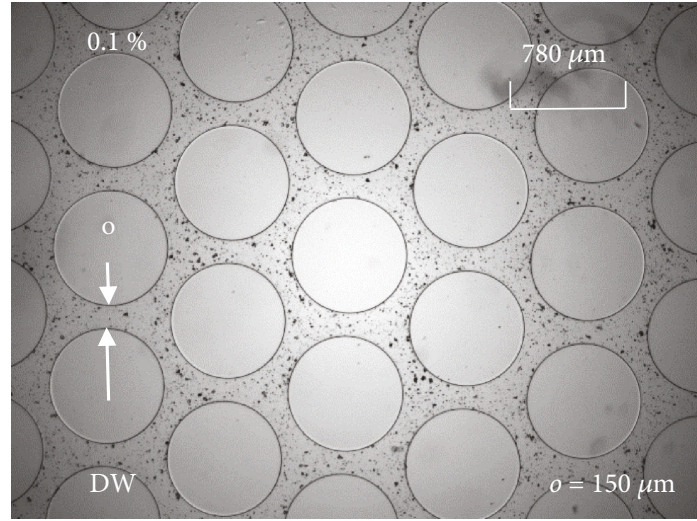

(a)

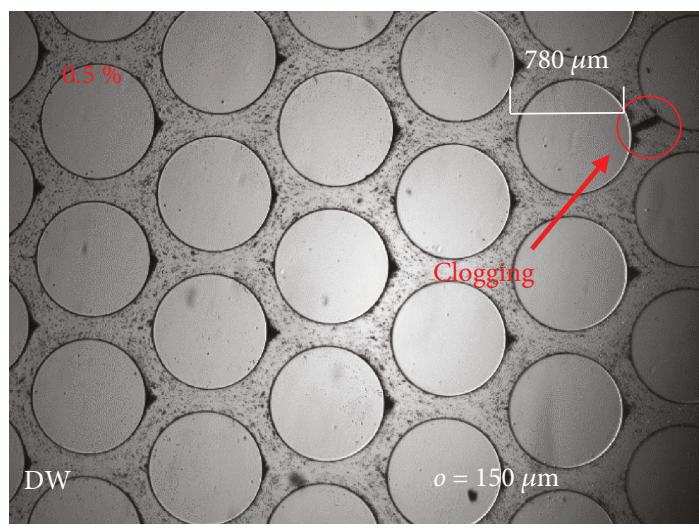

(c)

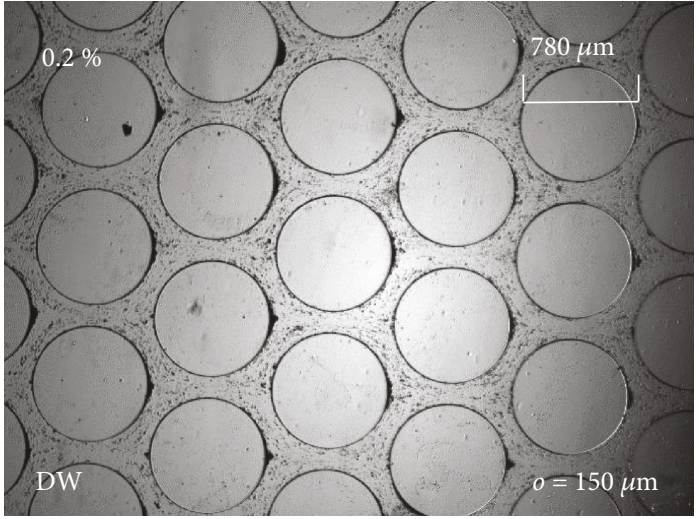

(b)

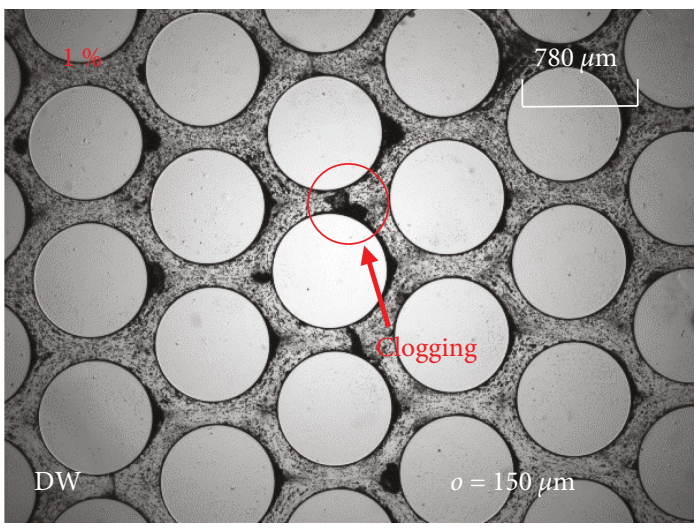

(d)

FIgURE 3: Particle concentration effects on clogging behaviors in pore throats during DW flow with diatom.

data from 0.04 to 0.2 (Figure 4). In contrast, the critical clogging concentration of kaolinite in $2 \mathrm{M}$-brine is higher than in DI water when the fine pore throat size ratio is less than 0.04 . The results demonstrate that kaolinite forms aggregation more easily in DW than in 2M-brine, which can be explained by Coulombic forces between platy particles that cause compact, face-to-face aggregation of kaolinite particles in 2M-brine. However, kaolinite platy particles form bulky, edge-to-face aggregation in DW, which cause the kaolinite to form a bridge or clogging in pore throats.

However, the critical clogging concentration of kaolinite is similar between $2 \mathrm{M}$-brines and DW when the fine pore throat size ratio is higher than 0.04 , which shows the same trends in a previous study [8]. A higher fine pore throat size means a larger fine particle size. Thus, it implies that the large particle size governs the clogging in pores.

3.2.2. Silica Silt. While the size ratios of fine particle-pore throat were from 0.105 to 0.525 in the previous study [8], a broader range of size ratio is investigated in this study from 0.0525 to 0.525 . Experimental results in the range of size ratio from 0.0525 to 0.105 are added to the "clogging map" with the critical particle concentration. Figure 4 presents that the critical clogging concentration of silica silt in DW is higher than in $2 \mathrm{M}$ brine in all range of size ratios, which shows trends reported by [8]. The silica silt forms aggregations more easily in 2M-brine than in DW. Silica silt has a more negative charge distribution on the surface, which causes silica particles not to aggregate in freshwater. However, the positive ions in $2 \mathrm{M}$-brine decrease the interparticle repulsive force, which influences on the easier clogging of silica silt in $2 \mathrm{M}$-brines than in DW. The net attractive interaction in $2 \mathrm{M}$-brines is described by the Sogami-Ise model [31]. It implies that silica silt decreases their potential for forming bridges and blocks at the pore throat by freshwater during gas production from hydrate-bearing sediments.

3.2.3. Bentonite. The size ratios of fine particle pore throat were from 0.02 to 0.1 in the previous study [8], and the broader range of the size ratio is reported in this paper from 0.01 to 0.1 . Note that the range of size ratios from 0.01 to 0.02 is added to Figure 4. Experimental results in the range of size ratio from 0.01 to 0.02 are added to the "clogging map" with the critical particle concentration of bentonite particles. Figure 4 shows that the critical clogging concentration of bentonite in DW is much higher than in 2M-brine in all range of size ratios, which shows the same trends reported by [8]. Bentonite aggregates more easily in $2 \mathrm{M}$-brine than in DW, which can be explained by double layer thickness of bentonite particles since bentonite particles have a high surface charge concentration and surrounded by a relatively thick double layer of freshwater [32], which is explained by a combination of Van der Waals attraction and double layer 


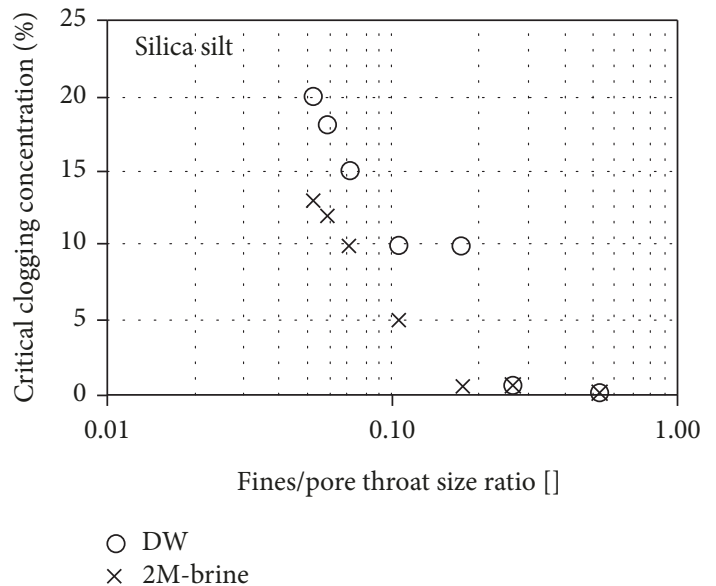

(a)

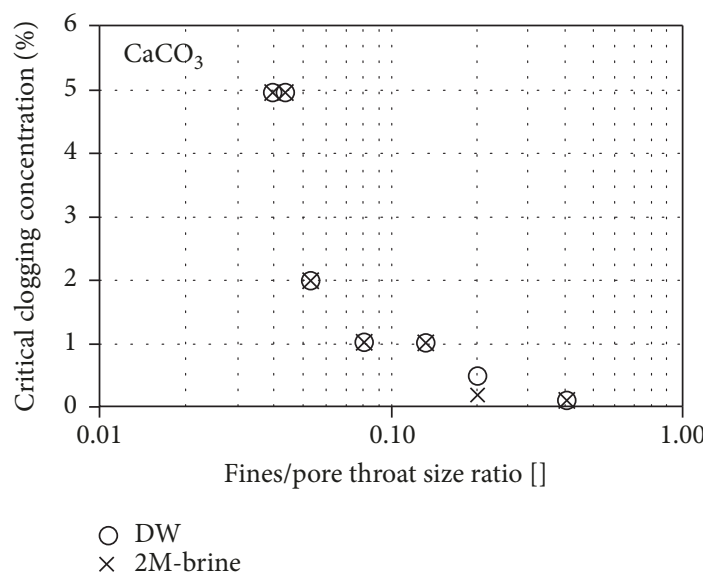

(c)

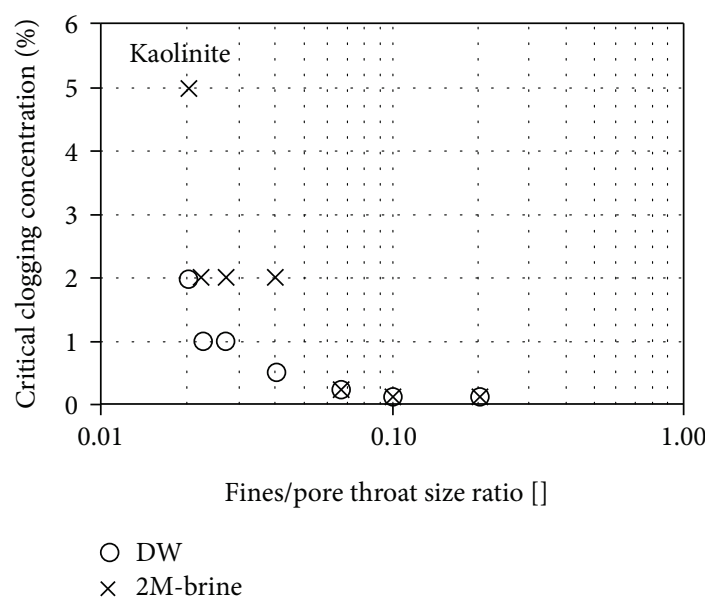

(e)

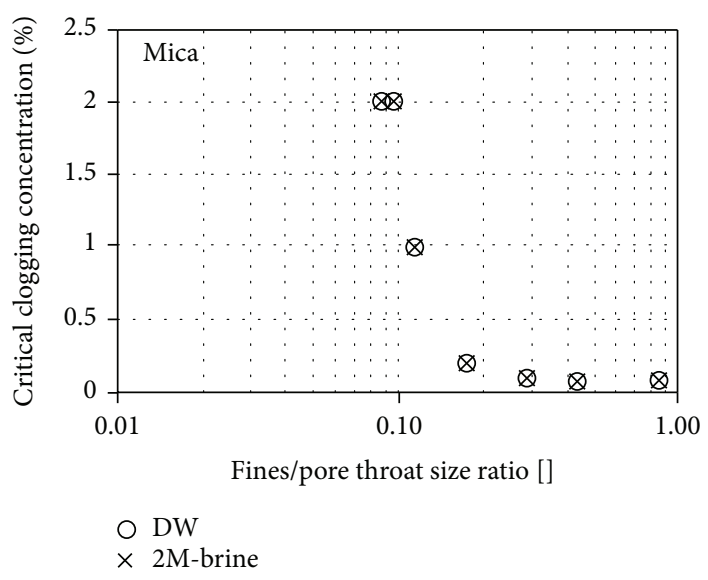

(b)

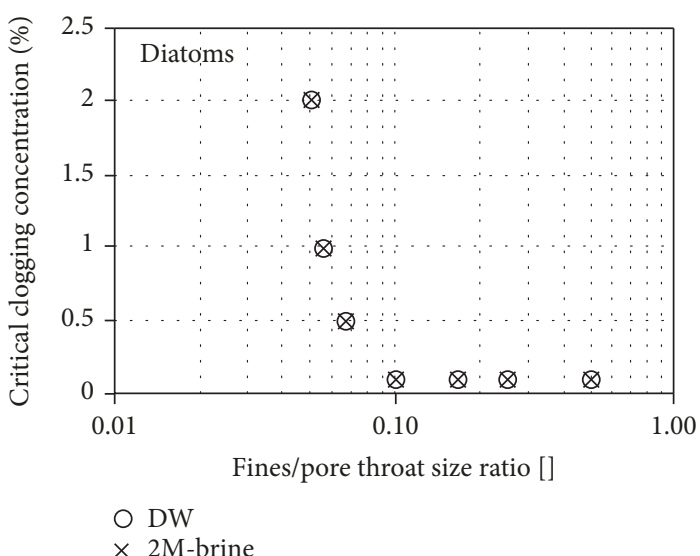

(d)

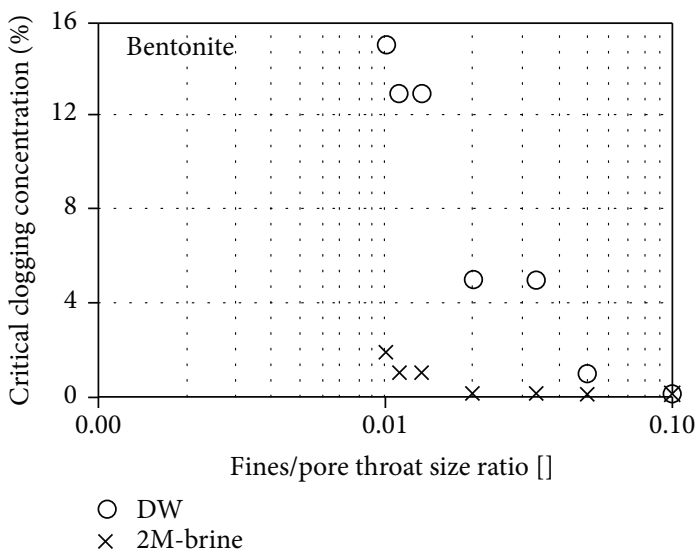

(f)

FIGURE 4: The effects of ionic concentration of fluids (DW or 2M-brine) on clogging behaviors in pore throats.

repulsion described by the DLVO theory. However, the double layer thickness decreases with the increased ionic concentration in water, which cause bentonite particles to form bridges and blocks at pore throats. It implies that bentonite particles decrease their potential for forming bridges and blocks at the pore throat by freshwater during gas production from hydrate-bearing sediments.
3.2.4. Mica, $\mathrm{CaCO}_{3}$, and Diatoms. Mica, $\mathrm{CaCO}_{3}$, and diatoms show the same critical particle concentrations between DW and 2M-brine in each size ratio of the fine particle pore throat. Mica, $\mathrm{CaCO}_{3}$, and diatom have a relatively large particle size (Table 1), which governs the interparticle interactions rather than electrical forces. Thus, clogging of relatively large particles such as mica, $\mathrm{CaCO}_{3}$, 

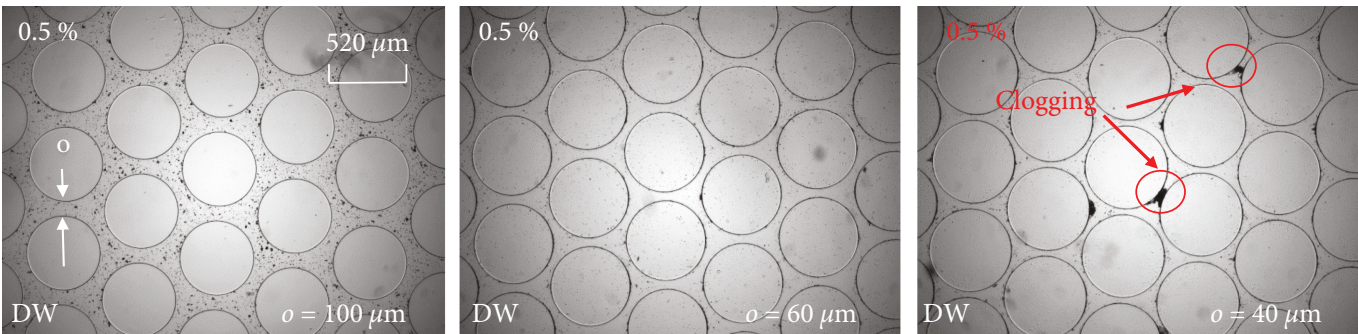

Figure 5: Pore throat size effects on clogging behaviors during DW flow with kaolinite.

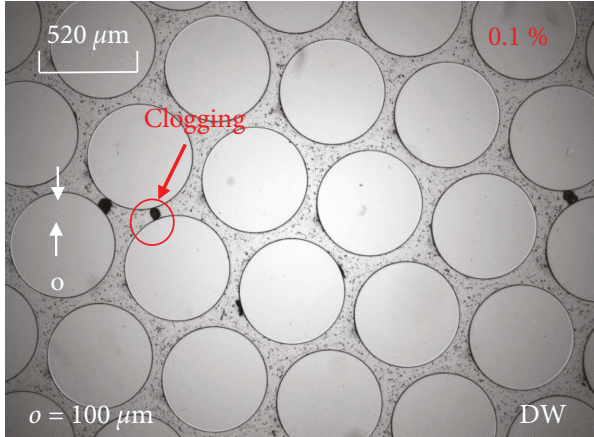

(a)

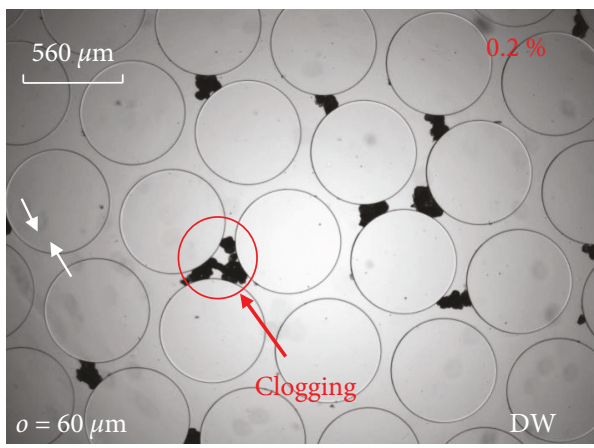

(c)

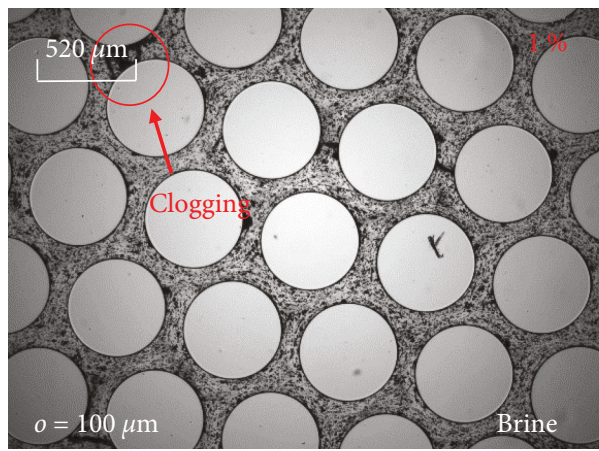

(e)

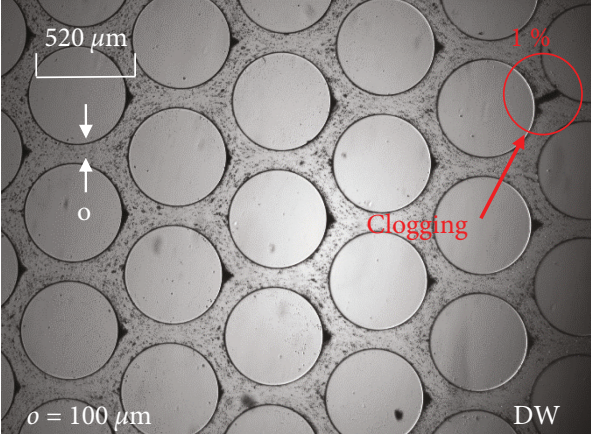

(b)

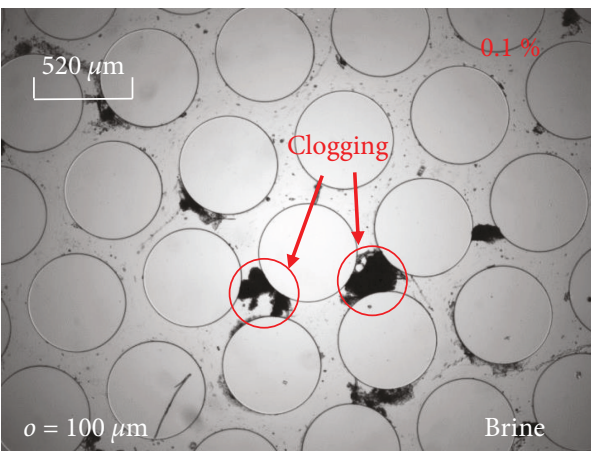

(d)

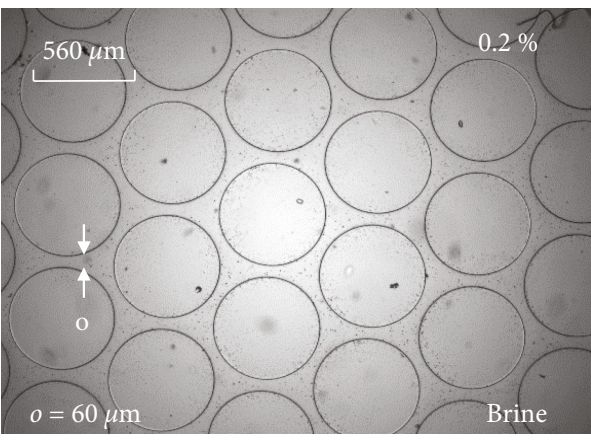

(f)

FIGURE 6: The effects of ionic concentration of fluid on clogging behaviors in pore throats. (a) DW with diatom, (b) $\mathrm{DW}$ with CaCO 3 , (c) $\mathrm{DW}$ with kaolinite, (d) $2 \mathrm{M}$-brine with diatom, (e) $2 \mathrm{M}$-brine with $\mathrm{CaCO}_{3}$, and (f) $2 \mathrm{M}$-brine with kaolinite.

and diatom is controlled by their particle shape. The results provided clear evidence that freshwater during hydrate dissociation does not influence aggregation of mica, $\mathrm{CaCO}_{3}$, and diatom particles.
3.3. Effects of Multiphase Fluid Flow on Fine Migration and Clogging Behavior. After the DW percolated the micromodel, $\mathrm{CO}_{2}$ gas was injected to simulate multiphase fluid flow during gas production from hydrate-bearing sediment. Gas 


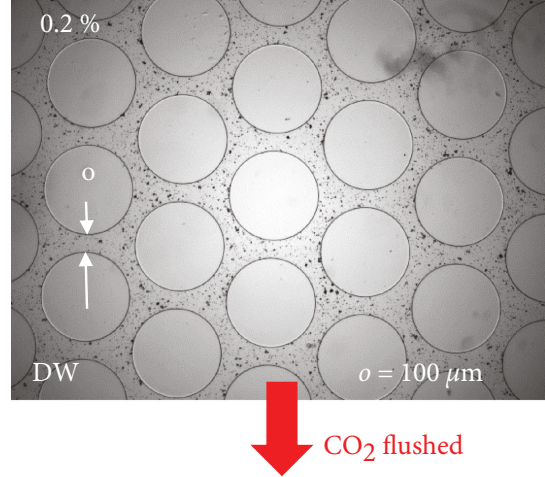

(a)

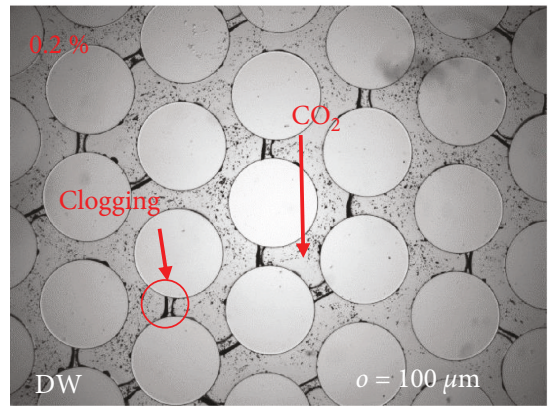

(d)

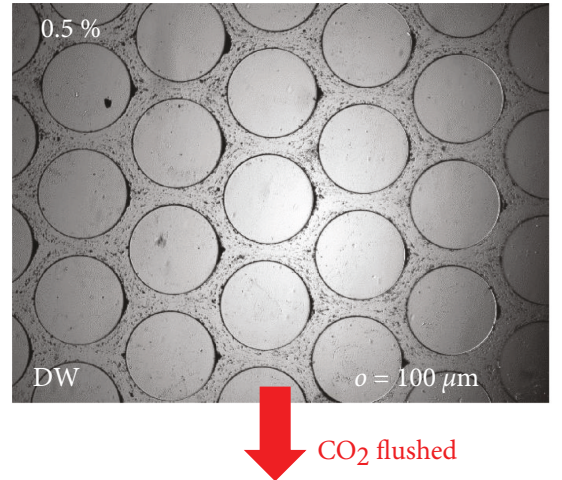

(b)

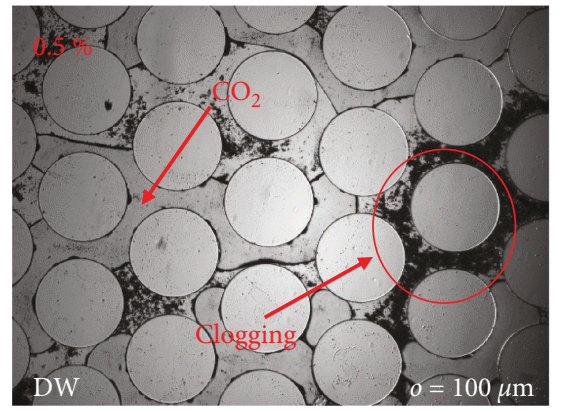

(e)

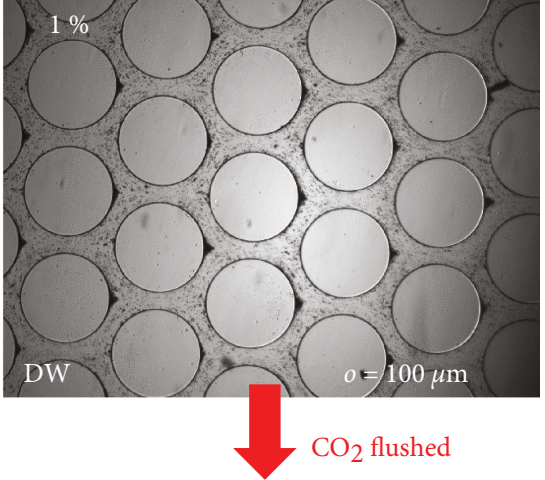

(c)

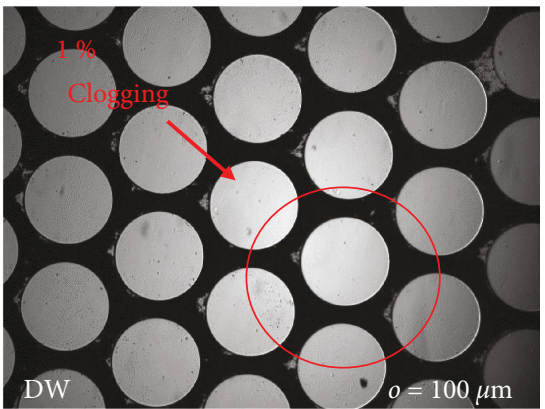

(f)

FIGURE 7: The effects of multiphase fluid flow on clogging behaviors in pore throats during DW or 2M-brine flow with kaolinite: (a) DW with $0.2 \%$ kaolinite, (b) DW with $0.5 \%$ kaolinite, (c) DW with $1 \%$ kaolinite, (d) DW- $\mathrm{CO}_{2}$ with $0.2 \%$ kaolinite, (e) $\mathrm{DW}-\mathrm{CO}_{2}$ with $0.5 \%$ kaolinite, and (f) $\mathrm{DW}-\mathrm{CO}_{2}$ with $1 \%$ kaolinite.

hydrate dissociation releases freshwater that decreases the ionic concentration in liquid during gas production. Therefore, only DW was used in multiphase fluid flow. Figure 7 shows a few images between single-phase flow and multiphase fluid flow. When DW with kaolinite at a given concentration from $0.2 \%$ to $1 \%$ was injected into the micromodel $(o=100 \mu \mathrm{m})$, no clogging was observed in Figures 7(a), $7(\mathrm{~b})$, and $7(\mathrm{c})$. Then, $\mathrm{CO}_{2}$ gas was injected into the micromodel with identical geometry and kaolinite concentration to explore the effects of multiphase fluid flow on migration and clogging behaviors of kaolinite particles (Figures 7(d), $7(\mathrm{e})$, and $7(\mathrm{f}))$. As $\mathrm{CO}_{2}$ gas was injected into the micromodel, it displaced DW which was already filling the pore space. $\mathrm{CO}_{2}$ gas-DW interfaces in the micromodel accumulated kaolinite particles as indicated by the dark leading edge in the micromodel, and kaolinite particles were migrating ahead of the $\mathrm{CO}_{2}$ gas front. Thus, the clogging occurred in pore throats as $\mathrm{CO}_{2}$ gas was injected. This result implies that kaolinite particles clog more easily in a multiphase fluid flow than in a single-phase flow.

Clogging of fine particles in multiphase fluid flow could locally increase the pressure in the pores during hydrate dissociation due to the decreased relative permeability, which could push the host particles in sediments and change the pore geometry [9]. While the results in this study do not show such a migration of host particles due to the fixed host particle in the micromodel, clogging observed during multiphase fluid flow could cause a fracture in natural sediment during gas production from hydrate-bearing sediments. The locally increased fine particle concentration along the interface and clogging can explain the fracture in the previous study by [9].

Figure 8 shows critical clogging concentrations of all types of fine particles (i.e., silica silt, mica, $\mathrm{CaCO}_{3}$, diatoms, kaolinite, and bentonite) between DW (single-phase flow) and DW- $\mathrm{CO}_{2}$ (multiphase fluids flow). Results show that (1) the critical clogging concentration is higher in DW than in DW- $\mathrm{CO}_{2}$ in all types of particles and all range of fine pore size ratios, and (2) when the particle size is relatively larger (i.e., fine-pore throat size ratio $>0.1$ ), the critical clogging concentration is similar between DW and $\mathrm{DW}-\mathrm{CO}_{2}$ because the particle size mainly governs the interparticle interactions.

\section{Conclusions}

Fine behavior in porous media broadly classified by four regions, namely, piping (no interaction), bridging, aggregation (blocking), and sieving (no invasion). Such classification is affected by fine particle-pore throat size ratio, fine particle concentration, ionic concentration of fluids, and multiphase fluid flow. Published data shows that neither clogging nor bridging was observed at a lower fine particle pore throat size 


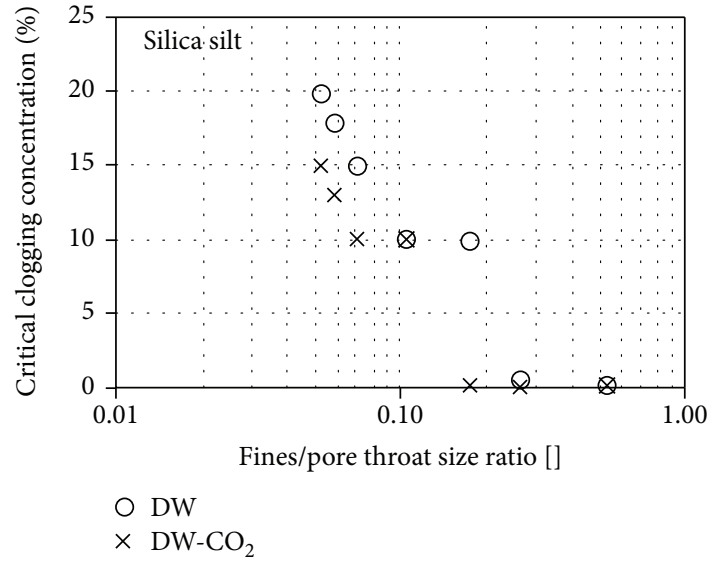

(a)

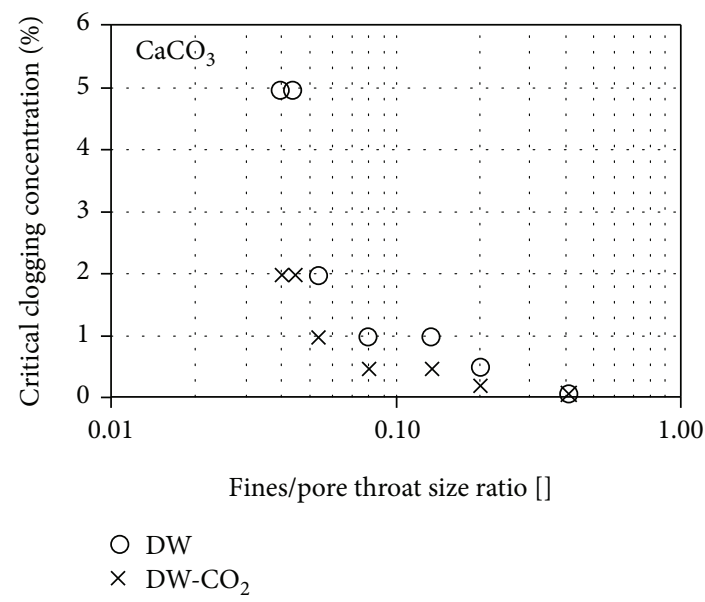

(c)

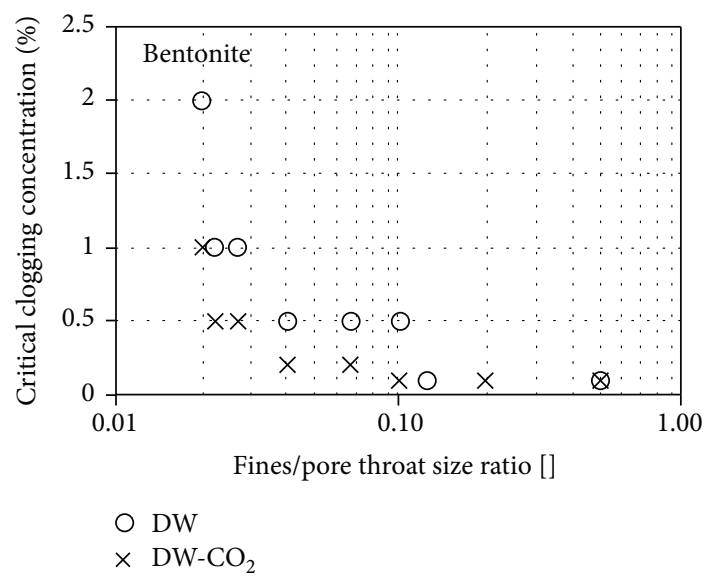

(e)

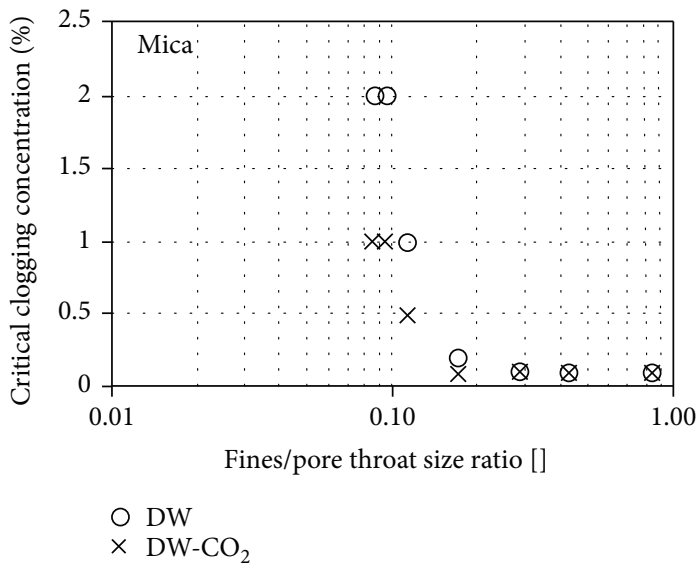

(b)

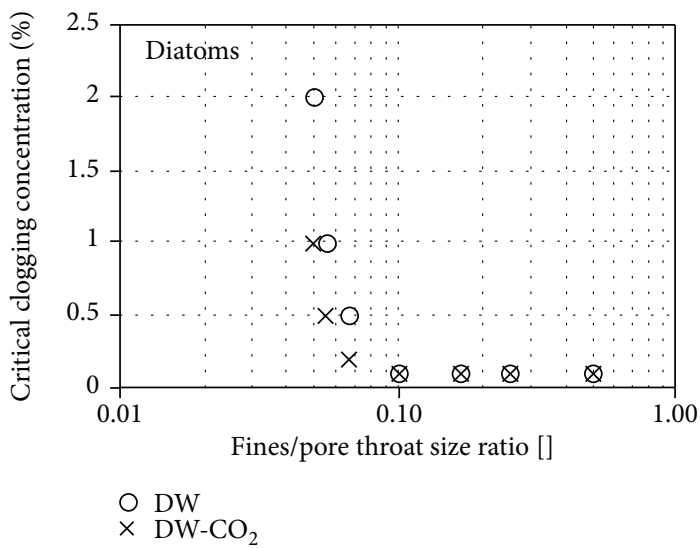

(d)

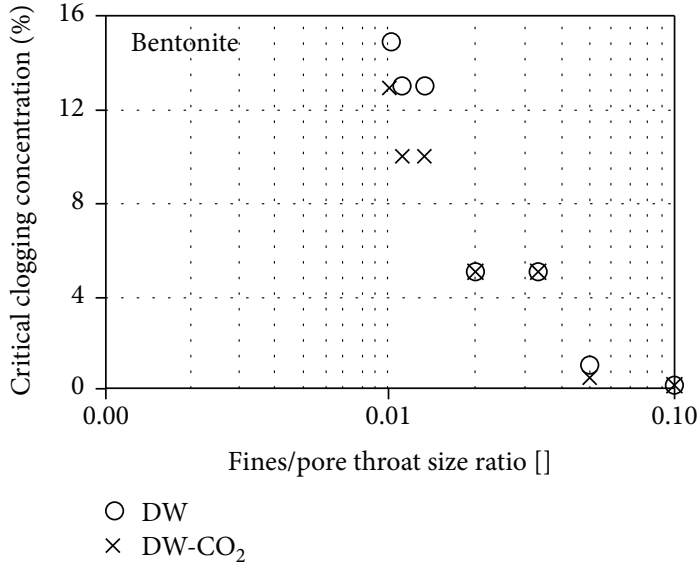

(f)

FIgURE 8: The effects of multiphase fluid flow on clogging behaviors in pore throats.

ratio. However, recent studies show that clogging occurs even at a lower fine particle pore throat size ratio with a multiphase fluid flow and the change in ionic concentration of liquid. Previous studies did not present enough measurements to cover a broad range of particle types and sizes and pore throat size in natural hydrate-bearing sediments. This paper presents the results of a novel micromodel that was developed to investigate the impact of fine particle pore throat size ratio, fine concentration, ionic concentration of fluid, and multiphase fluid flow on clogging or bridging in porous media.

Single-phase flow experiments were conducted with more percentages of fine particle concentration and fine particle pore throat size ratio than what was published in 
previous studies. The results show that the concentration of fine particles required to form clogging and/or bridging in pores decreased with the decrease in fine particle pore throat size ratio.

The impact of ionic concentration of fluid on clogging behavior depends on the types of fine particles. Kaolinite easily clogged the pore throat in DW than in 2M-brine, which could be explained by Coulombic forces between platy particles that cause compact, face-to-face clusters of kaolinite particles in 2M-brine. On the contrary, silica silt clogged the pore space in $2 \mathrm{M}$-brine easier than in DW, which is attributed to the negative charge distribution of silica silt on the surface. The positive ions in 2M-brine decrease the interparticle repulsive force between the silica particles and cause aggregations followed by clogging at the pore throat in $2 \mathrm{M}$ brines. Clogging develops easily for bentonite in 2M-brine than in DW which can be explained by a relatively thick double layer around the bentonite particles. Others such as mica, $\mathrm{CaCO}_{3}$, and diatoms exhibit the same critical particle concentrations for fines in DW and 2M-brine due to the relatively large particle size, which governs the interparticle interactions rather than electrical forces.

Multiphase fluid flow experiments show that fine particles prefer to accumulate along the $\mathrm{DW}-\mathrm{CO}_{2}$ interface and migrate together, which in turn easily cause clogging in pores. This result implies that multiphase fluid flow during gas production from hydrate-bearing sediments could easily form clogging in pore throats, where the relative permeability of $\mathrm{DW} / \mathrm{CO}_{2}$ in porous media decreases. Also, the fracture could occur due to the increased pressure by the clogging in pores. Thus, the relative permeability of porous media should be evaluated by considering the clogging behavior of fines.

The results imply that the decrease in the salinity and the presence of the gas phase induced from gas hydrate production can damage the formation permeability and thus reduce the productivity. The measure for preventing pore clogging should be developed for sustainable gas production in the presence of fines in the reservoirs.

\section{Data Availability}

The data used to support the findings of this study are available from the corresponding author upon request.

\section{Disclosure}

The findings achieved herein are solely the responsibility of the authors.

\section{Conflicts of Interest}

The authors declare that they have no conflicts of interest.

\section{Acknowledgments}

This research was made possible by an NPRP grant \# NPRP8594-2-244 from the Qatar National Research Fund (a member of Qatar Foundation). Also, this research was supported by a grant (2018-MOIS31-009) from the Fundamental
Technology Development Program for Extreme Disaster Response funded by the Korean Ministry of the Interior and Safety (MOIS) and by the Basic Science Research Program through the National Research Foundation of Korea (NRF) funded by the Ministry of Education (2017R1D1A3B03 031369). This research was supported by the Ministry of Trade, Industry, and Energy (MOTIE) through the Project "Gas Hydrate Exploration and Production Study (19-1143)" under the management of the Gas Hydrate Research and Development Organization (GHDO) of Korea and the Korea Institute of Geoscience and Mineral Resources (KIGAM).

\section{References}

[1] C. Gruesbeck and E. Collins, "Entrainment and deposition of fine particles in porous media," Society of Petroleum Engineers Journal, vol. 22, no. 6, pp. 847-856, 1982.

[2] T. W. Muecke, "Formation fines and factors controlling their movement in porous media," Journal of Petroleum Technology, vol. 31, no. 2, pp. 144-150, 1979.

[3] G. Kampel, G. H. Goldsztein, and J. C. Santamarina, "Plugging of porous media and filters: maximum clogged porosity," Applied Physics Letters, vol. 92, no. 8, article 084101, 2008.

[4] J. C. McDonald and G. M. Whitesides, "Poly(dimethylsiloxane) as a material for fabricating microfluidic devices," Accounts of Chemical Research, vol. 35, no. 7, pp. 491-499, 2002.

[5] J. R. Valdes and J. C. Santamarina, "Clogging: bridge formation and vibration-based destabilization," Canadian Geotechnical Journal, vol. 45, no. 2, pp. 177-184, 2008.

[6] E. Papamichos, I. Vardoulakis, J. Tronvoll, and A. Skjaerstein, "Volumetric sand production model and experiment," International Journal for Numerical and Analytical Methods in Geomechanics, vol. 25, no. 8, pp. 789-808, 2001.

[7] H. Shin and J. C. Santamarina, "Fluid-driven fractures in uncemented sediments: underlying particle-level processes," Earth and Planetary Science Letters, vol. 299, no. 1-2, pp. 180-189, 2010.

[8] S. C. Cao, J. Jang, J. Jung, W. F. Waite, T. S. Collett, and P. Kumar, "2D micromodel studies of pore-throat clogging by pure fine-grained sediments and natural sediments from NGHP-02, Offshore India," in U.S. Geological Survey data release, Marine and Petroleum Geology, 2018.

[9] J. W. Jung, J. Jang, J. C. Santamarina, C. Tsouris, T. J. Phelps, and C. J. Rawn, "Gas production from hydrate-bearing sediments: the role of fine particles," Energy \& Fuels, vol. 26, no. 1, pp. 480-487, 2012.

[10] G. C. Agbangla, É. Climent, and P. Bacchin, "Experimental investigation of pore clogging by microparticles: evidence for a critical flux density of particle yielding arches and deposits," Separation and Purification Technology, vol. 101, pp. 42-48, 2012.

[11] J. R. Valdes, "Fine migration and formation damagemicroscale studies," Civil Engineering, Geoogia Institute of Technology, 2002, Doctor of Philosophy.

[12] Y. Bigno, M. B. Oyeneyin, and J. M. Peden, "Investigation of pore-blocking mechanism in gravel packs in the management and control of fines migration," in Proceedings of Society of Petroleum Engineers International Symposium on Damage Control, vol. 9no. 10, pp. 29-40, Lafayette, Louisiana, 1994. 
[13] E. Dressaire and A. Sauret, "Clogging of microfluidic systems," Soft Matter, vol. 13, no. 1, pp. 37-48, 2017.

[14] K. C. Khilar and H. S. Fogler, "Migrations of fines in porous media," in Theory and Applications of Transport in Porous Media, Kluwer Academic Publishers, 1998.

[15] M. B. Oyeneyin, J. M. Peden, A. Hosseini, and G. Ren, "Factors to consider in the effective management and control of fines migration in high permeability sands," in SPE European Formation Damage Conference, pp. 15-16, The Hague, 1995.

[16] M. Xiao and N. Shwiyhat, "Experimental investigation of the effects of suffusion on physical and geomechanic characteristics of sandy soils," Geotechnical Testing Journal, vol. 35, no. 6, p. 104594, 2012.

[17] L. T. Fan, R. Nassar, S. H. Hwang, and S. T. Chou, "Analysis of deep bed filtration data: modeling as a birth-death process," AIChE Journal, vol. 31, no. 11, pp. 1781-1790, 1985.

[18] J. P. Herzig, D. M. Leclerc, and P. L. Goff, "Flow of suspensions through porous media-application to deep filtration," Industrial \& Engineering Chemistry, vol. 62, no. 5, pp. 8-35, 1970.

[19] A. O. Imdakm and M. Sahimi, "Computer simulation of particle transport processes in flow through porous media," Chemical Engineering Science, vol. 46, no. 8, pp. 1977-1993, 1991.

[20] K. C. Khilar and H. S. Fogler, "Colloidally induced fines migration in porous media," Reviews in Chemical Engineering, vol. 4, no. 1-2, pp. 213-221, 1987.

[21] R. I. Mackie, R. M. W. Horne, and R. J. Jarvis, "Dynamic modeling of deep-bed filtration," AIChE Journal, vol. 33, no. 11, pp. 1761-1775, 1987.

[22] S. D. Rege and H. S. Fogler, "A network model for deep bed filtration of solid particles and emulsion drops," AIChE Journal, vol. 34, no. 11, pp. 1761-1772, 1988.

[23] M. M. Sharma and Y. C. Yortsos, "Fines migration in porous media,” AIChE Journal, vol. 33, no. 10, pp. 1654-1662, 1987.

[24] S. K. Bhuniya, "Flow of suspension through packed beads: studies on the influences of the particle concentration. M. Tech. Thesis," IIT Bombay, 1996.

[25] V. B. Pandya, S. Bhuniya, and K. C. Khilar, "Existence of a critical particle concentration in plugging of a packed bed," AIChE Journal, vol. 44, no. 4, pp. 978-981, 1998.

[26] J. W. Jung, S. C. Cao, Y. H. Shin, R. I. Al-Raoush, K. Alshibli, and J. W. Choi, "A microfluidic pore model to study the migration of fine particles in single-phase and multiphase flows in porous media," Microsystem Technologies, vol. 24, no. 2, pp. 1071-1080, 2018.

[27] G. Han, T. H. Kwon, J. Y. Lee, and T. J. Kneafsey, "Depressurization-induced fines migration in sediments containing methane hydrate: X-ray computed tomography imaging experiments," Journal of Geophysical Research: Solid Earth, vol. 123, no. 4, pp. 2539-2558, 2018.

[28] J. J. Bahk, D. H. Kim, J. H. Chun et al., "Gas hydrate occurrences and their relation to host sediment properties: results from second Ulleung Basin gas hydrate drilling expedition, east sea," Marine and Petroleum Geology, vol. 47, pp. 21-29, 2013.

[29] K. Egawa, O. Nishimura, S. Izumi et al., "Bulk sediment mineralogy of gas hydrate reservoir at the East Nankai offshore production test site," Marine and Petroleum Geology, vol. 66, pp. 379-387, 2015.

[30] W. J. Winters, R. W. Wilcox-Cline, P. Long et al., "Comparison of the physical and geotechnical properties of gas-hydratebearing sediments from offshore India and other gas-hydrate- reservoir systems," Marine and Petroleum Geology, vol. 58, pp. 139-167, 2014.

[31] I. Sogami and N. Ise, "On the electrostatic interaction in macroionic solutions," The Journal of Chemical Physics, vol. 81, no. 12, pp. 6320-6332, 1984.

[32] G. Sposito, The Chemistry of Soils, Oxford University Press, New York, 1989. 

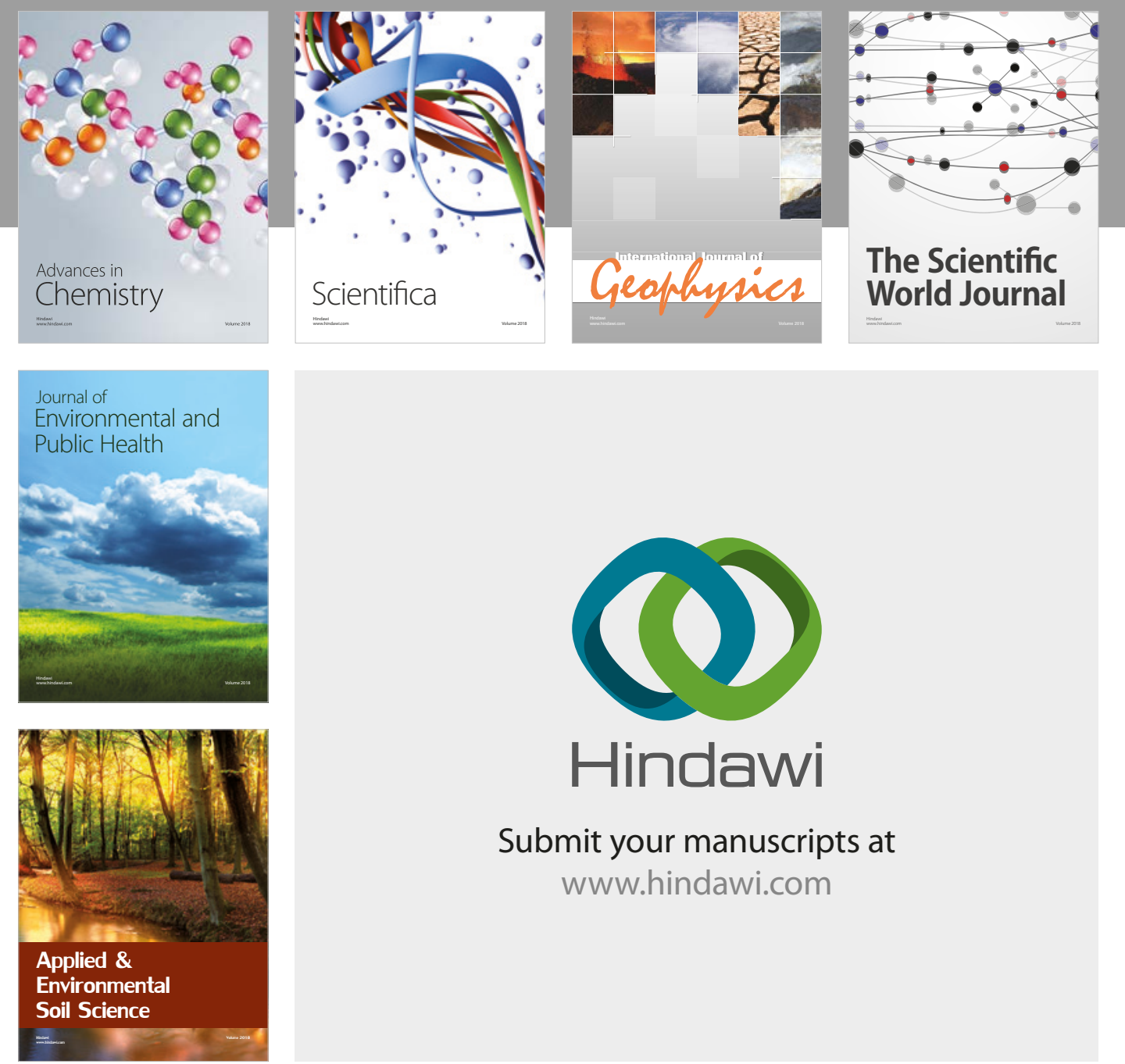

The Scientific

\section{World Journal}
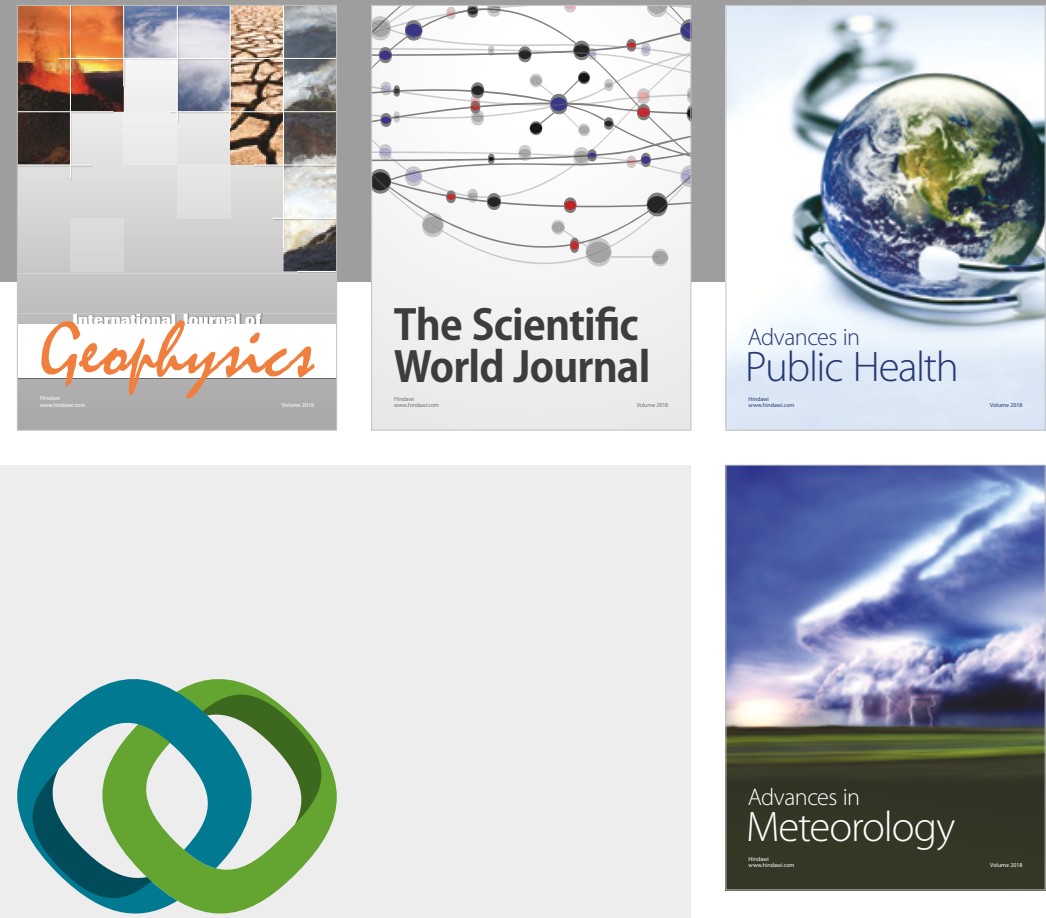

Advan

Public Health

\section{Hindawi}

Submit your manuscripts at

www.hindawi.com
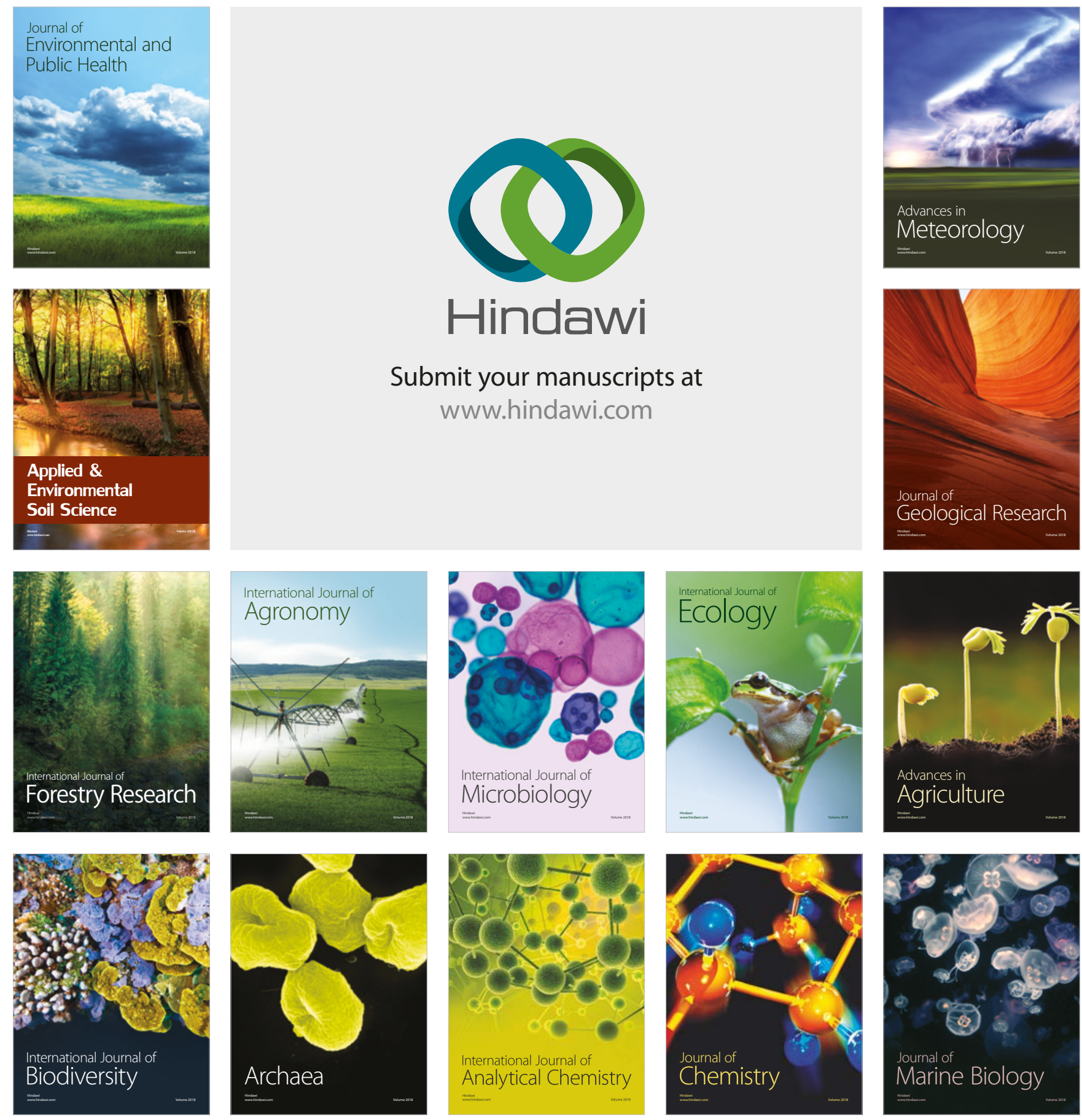